\title{
A representação política das mulheres nos Conselhos Gestores de Políticas Públicas
}

\author{
Lígia Helena Hahn Lüchmann \\ Universidade Federal de Santa Catarina (UFSC)
}

\author{
Carla Cecília Rodrigues Almeida \\ Universidade Estadual de Maringá (UEM)
}

\begin{abstract}
A representação política das mulheres nos Conselhos Gestores de Políticas Públicas
Resumo: Este trabalho levanta algumas hipóteses para explicar a significativa presença das mulheres nos Conselhos Gestores de Políticas Públicas, espaços de discussão e deliberação de políticas que foram implementados no Brasil nas últimas décadas. Os dados sobre o perfil dos representantes nestes espaços apontam para um quadro inversamente proporcional, em termos numéricos, ao baixo grau de inclusão política das mulheres nos espaços tradicionais de representação política - Executivos, Câmara de Vereadores e Assembleias Legislativas. Eles desafiam, portanto, o desenvolvimento de novas ferramentas analíticas para o entendimento do fenômeno da representação política, na mesma medida em que problematizam um diagnóstico que, centrado em uma perspectiva redutora da ação e do campo político, conclui pela manutenção de uma baixa taxa de inclusão política das mulheres.

Palavras-chave: representação política, Conselhos Gestores, participação, feminismo.
\end{abstract}

\section{The Political Representation of Women in Public Policy Management Councils}

Abstract: This work raises some hypotheses to explain the significant presence of women on public policy management councils, which are spaces for discussion and deliberation of policies that have been implemented in Brazil in recent decades. The data about the profile of representatives on these spaces indicates a situation inversely proportional to the low degree of political inclusion of women in traditional spaces of political representation - executive positions, city councils, and state legislatures. There is thus a need to develop new analytical tools to understand the phenomenon of political representation. The data also question a reductive perspective of action and politics, which concludes that there is a low degree of political inclusion of women.

Key words: political representation, management councils, participation, feminism. 


\section{Introdução}

Os movimentos feministas e a teoria política feminista contestaram, nas últimas décadas, uma série de pressupostos construídos e perpetuados por várias vertentes do pensamento ocidental a respeito das relações entre as mulheres e a política. Como resultado, a teoria feminista contribuiu para a própria ampliação do conceito de política, tradicionalmente entendido como o campo relativo às instituições político-estatais no qual os atores alcançam, via competição eleitoral, a legitimidade para definir as leis e as ações governamentais. Questionando a separação rígida entre o mundo público e o privado que fundamentava aquele entendimento, as feministas contribuíram para mostrar que a política e o poder também estavam presentes em atividades humanas e relações sociais costumeiramente definidas como não pertencentes ao terreno das preocupações públicas.

Além disso, os estudos feministas também ofereceram explicações alternativas aos dados que comprovam as diferenças numéricas dos gêneros na representação política institucional. Tais dados não seriam evidências de que as mulheres se interessam menos por política do que os homens, ou de que sejam menos participativas e possuam menor grau de conhecimento e de motivação para se inserir em atividades políticas. Esses dados, ao contrário, seriam sintomas dos processos históricos e culturais que, tendo excluído ou restringido a presença das mulheres na vida e nos assuntos públicos, dificultam até os dias correntes sua participação em partidos políticos e suas possibilidades de êxitos na competição eleitoral.

Neste artigo, tomamos como referência o perfil de representação encontrado nos Conselhos Gestores de Políticas Públicas para dialogar com aquelas contribuições e com outras preocupações que circundam o debate a respeito da participação e da representação política das mulheres. Fazendo uso de dados acerca do perfil dos representantes nos Conselhos Gestores de municípios catarinenses ${ }^{1}$, corroborados por outros estudos, pretende-se aqui não apenas problematizar o diagnóstico que aponta para a manutenção de uma baixa taxa de inclusão política das mulheres, como levantar algumas hipóteses que ajudem a explicar sua significativa presença naqueles novos espaços institucionais.

É certo que estamos tratando de Conselhos localizados nas áreas sociais, tradicionalmente consideradas femininas, o que poderia ser, a priori, o ponto central de nossa exploração. No entanto, sem desconsiderar essa variável e as questões que ela impõe para o debate das relações entre as mulheres e a política, sugerimos que a significativa presença feminina nos Conselhos está relacionada também à inovação trazida por estas instituições quanto aos procedimentos de escolha de representantes e aos significados específicos que são atribuídos a este tipo de representação, se comparados à representação eleitoral.

\section{Participação, representação e inclusão política das mulheres}

Uma vertente da literatura internacional postula que, em qualquer democracia, a maioria das pessoas é mal informada sobre política e não está interessada nos assuntos que lhes dizem respeito (DAHL, 1992; MILBRATH, 1972; VERBA; NIE, 1987). Fundamentalmente, isto se explicaria pelo fato de elas não se sentirem afetadas diretamente pela política e por viverem em um mundo de símbolos, mitos, rituais e outras impressões irreais e distorcidas do "verdadeiro" mundo político (BURKHART et al, 1972). Estes estudos estão ancorados em uma definição de sistema político enquanto um padrão persistente de relações humanas que envolvem poder, regras e autoridade, sendo a política entendida como processo de tomada das decisões governamentais (MILBRATH, 1972).

Embora se reconheça a complexidade de fatores e variáveis que conformam o fenômeno da participação política, aquela literatura aponta que um dos seus mais importantes preditores diz respeito ao perfil socioeconômico dos participantes. Pesquisas em diferentes países atestam a importante correlação entre educação, renda e ocupação, cuja combinação positiva permite maior propensão, interesse, capacidade e disposição à participação política. A educação é apontada como o fator mais importante, na medida em que o cidadão com maior nível de escolaridade teria mais informação e maior capacidade para emitir opinião política; seria mais engajado e sentiria menos constrangimento para falar e participar de grupos e de associações; sentiria maior capacidade de influenciar o governo e mais confiança nos outros e em si próprio (MILBRATH, 1972, p. 123).

Esta correlação entre participação e status socioeconômico é mediada pelos custos que geralmente são proporcionais à intensidade da participação. De acordo com Burkhart et al (1972), o custo mais óbvio é o tempo. Participação política toma tempo (contatos, reuniões, etc), exige trabalho voluntário e compromisso pessoal ${ }^{2}$. Além disso, os autores ressaltam os custos emocionais que requerem a participação política, entre eles, as desilusões pelo não retorno do dispêndio de alta energia e investimento; as hostilidades enfrentadas no mundo da política (oposições, ataques pessoais, discriminações, etc.); as pressões e as ansiedades que pesam sobre os indivíduos nos processos de tomadas de decisões.

Tais custos seriam particularmente importantes para explicar as taxas diferenciadas de participação política no que se refere ao gênero. As atividades 
voltadas aos cuidados da vida doméstica registram diferentes responsabilidades e recursos nas relações de gênero, resultantes, como já se apontou, dos processos históricos de socialização que conduziram, de forma dramática, à configuração do monopólio masculino de apropriação do território da política. De fato, a persistente ausência ou subrepresentação das mulheres nas posições de poder deve-se, em larga medida, à associação entre o feminino e o espaço doméstico, e entre o masculino e o espaço da grande política - o espaço da competição e da liderança para a alocação autorizativa dos recursos da sociedade (CONWAY; STEUERNAGEL; AHERN, 2005). De acordo com Phillips (1991), a invisibilidade das mulheres na política deve ser entendida a partir de uma perspectiva multicausal, na medida em que processos de socialização e de constrangimentos culturais caminham lado a lado com os processos e constrangimentos político-institucionais (sistemas eleitorais, conformação dos partidos políticos, legislação etc.).

Contrastando com tais conclusões, os diagnósticos produzidos recentemente sobre o perfil da representa- ção nos Conselhos Gestores de Políticas Públicas evidenciam que, nestas instâncias, há uma significativa presença feminina quando comparadas às instituições tradicionais de representação política, como os Poderes Executivo e Legislativo ${ }^{3}$. Pode-se observar os dados expostos nas tabelas que indicam: tabela $1 \mathrm{o}$ perfil dos representantes por renda, escolaridade e gênero de alguns Conselhos Municipais do Estado de Santa Catarina em comparação com o perfil dos seus eleitores, e tabela 2 a composição, por gênero, dos Conselhos Municipais de Concórdia.

Como se percebe, a composição por sexo demonstra um amplo predomínio das mulheres. Comparando com a representação política feminina nos legislativos (municipal, estadual e federal), percebe-se uma inversão na composição do quadro. No caso dos legislativos, a ocupação de cadeiras por mulheres não tem passado, em média, a marca dos $10 \%$. Em todos os Conselhos estudados nos municípios de Itajaí e Chapecó, a participação das mulheres é majoritária, ainda que ela seja maior nos Conselhos Municipais de Assistência Social (CMAS), $80 \%$, e menor nos Conselhos Municipais

Tabela 1 - Renda, escolaridade e sexo dos eleitores e dos conselheiros ${ }^{4}$ dos municípios de Itajaí e Chapecó $(\%)$

\begin{tabular}{|l|l|l|l|l}
\hline & \multicolumn{3}{|c|}{ Chapecó } & \multicolumn{2}{c}{ Itajaí } \\
\hline $\begin{array}{l}\text { Escolaridade } \\
\text { Analfabeto }\end{array}$ & Município & Conselhos & Município & Conselhos \\
\hline $1^{\circ}$ grau incomp. & 2,29 & 0,0 & 1,50 & 0,0 \\
\hline $1^{\circ}$ grau compl. & 46,41 & 1,42 & 41,05 & 3,12 \\
\hline $2^{\circ}$ grau incomp. & 10,77 & 2,85 & 14,25 & 4,68 \\
\hline $2^{\circ}$ grau comp. & 20,16 & 0,0 & 18,69 & 7,81 \\
\hline $3^{\circ}$ grau incomp. & 12,64 & 12,85 & 15,73 & 6,25 \\
\hline $3^{\circ}$ grau comp. & 3,59 & 7,14 & 4,36 & 10,93 \\
\hline Total & 4,14 & 75,71 & 4,42 & 67,18 \\
\hline Renda & 100,0 & 100,0 & 100,0 & 100,0 \\
\hline Sem renda & & & & \\
\hline Menos de 1 SM & 33,56 & 0,0 & 36,60 & 0,0 \\
\hline 1 a 3 SM & 16,27 & - & 8,95 & - \\
\hline 3 a SM & 27,45 & - & 25,50 & - \\
\hline 5 a 10 SM & 9,34 & 34,28 & 11,19 & 26,15 \\
\hline Acima de 10 & 8,28 & 31,42 & 10,14 & 32,30 \\
\hline NS/NR & 5,10 & 10,0 & 5,63 & 23,07 \\
\hline Total & 0,0 & 24,28 & 0,0 & 18,46 \\
\hline Sexo & 100,0 & 100,0 & 100,0 & 100,0 \\
\hline Masculino & & & & \\
\hline Feminino & 48,33 & 25,7 & 47,69 & 29,2 \\
\hline Total & 51,67 & 74,3 & 52,31 & 70,8 \\
\hline
\end{tabular}

Fonte: para os dados dos Conselhos: pesquisa Conselhos Gestores e Empoderamento. Para os dados de escolaridade, renda, gênero e estado civil dos municípios, cadastro de eleitores do TRE/SC, disponíveis em: <http://www.tre sc.gov.br/ site/fileadmin/arquivos/eleicoes/estatistica_eleitoral/estat_offline/index.htm>.

Para os dados de renda dos municípios, IBGE Cidades (renda dos acima de 10 anos), disponíveis em: <http:// www.ibge.gov.br/cidadesat/default.php>. 
Tabela 2 - Sexo (Conselhos Municipais de Concórdia)

\begin{tabular}{|l|c|c|c|c|c|c|c|c|c|}
\hline \multirow{2}{*}{} & \multicolumn{2}{|c|}{ CMAS } & \multicolumn{2}{|c|}{ CMDCA } & \multicolumn{3}{c|}{ CMS } & \multicolumn{2}{c|}{ TOTAL } \\
\cline { 2 - 10 } & N & Fr & N & Fr & N & Fr & N & Fr \\
\hline Feminino & 13 & $61,9 \%$ & 10 & $71,4 \%$ & 7 & $43,7 \%$ & 30 & $58,8 \%$ \\
\hline Masculino & 8 & $38,1 \%$ & 4 & $28,6 \%$ & 9 & $56,3 \%$ & 21 & $41,2 \%$ \\
\hline Total & 21 & 100,00 & 14 & 100,00 & 16 & 100,00 & 51 & 100,00 \\
\hline
\end{tabular}

Fonte: Lüchmann e Borba (2009).

de Saúde (CMS), 66,7\%. Nos Conselhos Municipais de Direito da Criança e Adolescente (CMDCA), as mulheres ocupam 78,6\% das cadeiras e, nos Conselhos Municipais do Idoso (CMI), 71,4\%. No caso do município de Concórdia, a prevalência feminina é verificada no CMDCA por $71,4 \%$, e no CMAS por $61,9 \%$. No CMS, a participação masculina se sobrepõe, estando as mulheres, com 43,7\% das representações. Mesmo assim, os dados comprovam uma proporcionalidade maior da presença feminina nessas instâncias quando comparadas às instâncias tradicionais de representação. O diferencial quanto à representatividade feminina chama a atenção, sobretudo, porque se percebe que, nos Conselhos Gestores, a elitização da representação se mantém em relação à escolaridade e à renda, como demostram os dados da tabela 1. Assim, embora existam variações, os dados apontam para a subrepresentação de alguns segmentos que tradicionalmente têm sido alvos do discurso da democracia participativa, ancorado no princípio da inclusão dos setores mais pobres da população ${ }^{5}$.

Com efeito, para os municípios catarinenses investigados, em que pesem algumas variações, quando tomamos os dados relativos à idade, estado civil, número de filhos, religião, sexo e cor da pele, o perfil geral dos representantes conselhistas indica o "predomínio da conselheira mulher, com faixa de 40 anos, alta escolaridade, casada, católica e branca". Outras pesquisas, com diferentes recortes territoriais e temáticos, têm apontado para dados semelhantes. Como exemplo, nos CMDCAs, CMASs, CMSs e nos Conselhos de Trabalho e Educação (Fundef) de alguns municípios paranaenses, chegou-se a conclusão de que neles há uma leve preponderância de mulheres, de indivíduos maiores de 30 anos, casados(as), de religião católica, com alta escolaridade e que recebem mais de cinco salários mínimos (TONELLA, 2006).

Assim, embora reproduzindo outros traços de elitização, os Conselhos têm uma significativa representatividade das mulheres. A explicação para esse fenômeno exige explorar as especificidades que conformam tais instâncias, que se distanciam, de forma significativa, das configurações do sistema político eleitoral e não se enquadram nas concepções assentadas na dicotomia entre participação convencional e não convencional.

\section{Os Conselhos Gestores e suas novas modali- dades de participação e de representação política}

Os Conselhos são instâncias de discussão e deliberação de políticas públicas, amparadas por legislação nacional e que apresentam um desenho institucional estruturado e sistêmico, podendo atuar nas três esferas governamentais (município, estado e união). Suas atribuições são legalmente determinadas e incidem na formulação, implementação e fiscalização das políticas na respectiva esfera governamental onde atuam. Convém ressaltar duas características centrais da composição destes espaços: a paridade $^{6}$ na representação entre sociedade civil e Estado e a participação por representação de entidades ou organizações da sociedade civil.

Tais especificidades indicam dificuldades para se enquadrar os Conselhos Gestores (a despeito das diferenças entre eles) na distinção entre "participação política convencional e não convencional" tal como definem algumas análises (MILBRATH, 1972; VERBA; NIE, 1987). A primeira diz respeito às atividades relacionadas aos mecanismos governamentais de tomada de decisão, entre elas: votar em eleições, plebiscitos e referendos, participar de campanhas e partidos políticos, atuar como representante político. Por sua vez, a participação política "não convencional" diz respeito a um vasto conjunto de iniciativas e de atividades desenvolvidas por fora dos canais formais e da arena institucional, como as manifestações e protestos, as petições encaminhadas a órgãos públicos, a participação em movimentos sociais, ONGs etc. (BAQUERO; BORBA, 2008), marcando, portanto, uma atuação alternativa aos processos formais de encaminhamento de demandas sociais ao sistema político.

Os Conselhos apresentam finalidades e estruturas que, combinando elementos dos dois tipos acima elencados, desenham uma nova modalidade de participação política que, embora inscritos no âmbito do Estado, guardam suas bases de legitimidade, fundamentalmente, no âmbito da sociedade organizada. São espaços institucionais legais de discussão e deliberação de políticas públicas que instituem uma nova modalidade de representação política, caracterizada, 
fundamentalmente, pela combinação: a) da representação produzida pela participação direta em fóruns e b) representação intermediada por organizações da sociedade civil. Tais mecanismos de escolha variam de caso a caso, podendo resultar de uma assembleia com a participação de diferentes atores e organizações, de fóruns setoriais de políticas públicas ou de indicações de categorias profissionais.

Estas especificidades têm aberto um campo de pesquisa que procura decifrar as bases de legitimidade da representação conselhista, cuja escolha, diferentemente do processo eleitoral, não é feita por um "ato de autorização do público mais amplo" usuário das políticas públicas (ABERS; KECK, 2008; LAVALLE; CASTELO, 2008). A participação das organizações da sociedade civil neste processo fundamenta-se na ideia de que elas representariam "genuínos interesses sociais" e a escolha dos conselheiros, por seu intermédio, baseia-se em critérios variados: histórico nas lutas sociais pró-cidadania, competência técnica para deliberar assuntos de políticas públicas ou vinculação com um determinado segmento social (LÜCHMANN, 2007).

Não é intenção aqui analisar o conjunto das importantes interrogações e problemas que a bibliografia tem levantado acerca desta modalidade de representação. Nossa preocupação neste momento é específica: explorar os fatores que tornam esta modalidade de representação mais inclusiva às mulheres, se comparada ao modelo de representação do sistema eleitoral. Neste caso, devemos salientar seus contrastes mais evidentes com aquele sistema: a representação por intermediação de organizações da sociedade civil; os significados da atuação políticoinstitucional; e as áreas de políticas específicas em que estão inseridos.

\section{As mulheres, a representação eleitoral e a representação nos Conselhos Gestores: hipóteses exploratórias}

Os artigos do dossiê - Mulheres na Política, Mulheres no Poder, publicados pela Revista Estudos Feministas ${ }^{7}$, nos fornecem um valioso material de diagnóstico e de reflexão sobre os obstáculos que o sistema partidário e eleitoral impõe à participação das mulheres na política institucional brasileira. Como afirmaram vários daqueles artigos, tais obstáculos acabaram reduzindo significativamente os impactos da política de cotas implantada no país, em 1996, com o fim de ampliar a representação feminina nos Poderes Legislativos e Executivos. A resistência que as candidaturas femininas enfrentam no interior dos partidos políticos - expressa na falta de apoio financeiro e de recursos materiais e a reprodução de determinados padrões culturais que atribuem responsabilidades distintas e específicas para cada gênero, foram apontados como os fatores que mais dificultam a inclusão das mulheres na política partidária e seu sucesso na competição eleitoral (GROSSI; MIGUEL, 2001).

Sobre o primeiro fator, convém lembrar que os partidos costumam distribuir recursos desiguais para suas candidaturas de acordo com a posição que cada uma delas ocupa nas hierarquias de poder partidárias ou, ainda, de acordo com as potencialidades que têm de obter êxito na competição eleitoral. Contudo, como atestam depoimentos e análises contidos naquele dossiê, quando se trata de candidaturas femininas, muitas vezes a discriminação de gênero se sobrepõe à lógica eleitoral e as mulheres são, assim, mais afetadas pela falta de recursos e apoio na competição eleitoral.

Sobre o segundo fator, muitas mulheres inseridas na política institucional percebem que sua legitimidade nesse espaço está condicionada à capacidade de corresponder a um ideal ainda baseado nos atributos tradicionalmente associados ao gênero feminino, como a maternidade e a beleza. Por outro lado, vários artigos daquele dossiê concluíram que as mulheres têm mais chances de obter sucesso na competição eleitoral quando disputam cargos legislativos do que quando disputam cargos executivos. Elas enfrentam barreiras culturais para serem aceitas em cargos vistos com maior poder de decisão e comando (JUREMA, 2001).

No seu conjunto, os relatos e as análises encontrados na literatura nos sugerem algumas comparações entre a modalidade de escolha que preside o sistema eleitoral e a que preside a escolha dos conselheiros. Na competição partidária eleitoral, os candidatos e as candidatas se expõem à sociedade e, portanto, ao crivo dos valores culturais mais ampla e profundamente partilhados, cujas mudanças dependem de um tempo mais longo, e nem sempre seguem um ritmo contínuo e progressivo. Como vivemos numa sociedade que ainda atribui ao gênero feminino a responsabilidade de cuidar do ambiente doméstico e, ao masculino, do mundo público, esses últimos têm, evidentemente, mais chances de obter sucesso no crivo eleitoral. Ou seja, as chances das mulheres obterem audiência receptiva às suas candidaturas por parte do eleitorado, por mais que não defendam bandeiras feministas, são mais reduzidas quando competem ao lado de homens diante de toda a sociedade. Vale lembrar que, nesse sistema, a mídia tem feito cada vez mais a mediação entre, de um lado, candidatos e candidatas e, de outro, eleitores e eleitoras. Como atestam alguns estudos, tal mediação é vulnerável à reprodução dos valores culturais que restringem o papel das mulheres ao âmbito privado (FINAMORE; CARVALHO, 2006). 
Como contraponto, a escolha dos representantes dos Conselhos Gestores é, como vimos, mediada por organizações da sociedade civil e, em várias circunstâncias, resulta dos fóruns públicos das diversas áreas de políticas. Assim, para fazer parte dos Conselhos, os indivíduos não precisam passar pelo crivo de toda a sociedade, mas são escolhidos por suas organizações ou por outras com as quais compartilham, senão projetos políticos mais substantivos, pelo menos determinados princípios e ideias vigentes no campo de participação política nos quais estão inseridos. Aqui, mais do que indivíduos propriamente ditos, aqueles princípios e ideias é que estão em jogo na escolha dos representantes que, como vimos, segue geralmente três critérios: histórico nas lutas sociais prócidadania, competência técnica para deliberar assuntos de políticas públicas ou vinculação com um determinado segmento social.

Sugerimos, assim, que a significativa presença das mulheres nos Conselhos Gestores explica-se, como uma primeira via interpretativa, pelo procedimento de escolha de representantes típico destas instâncias, que ocorre fundamentalmente através da intermediação de organizações da sociedade civil. Esta intermediação funciona como um filtro que intercede sobre as discriminações de gênero, ainda que tal mediação não altere a elitização da participação quanto aos critérios baseados na escolaridade, na etnia e na renda. A intermediação da sociedade civil no processo de seleção de representantes faz mais exigências quanto às ideias e aos princípios que são compartilhados dentro de um mesmo campo de participação, enquanto que a competição eleitoral lança mais exigências aos atributos individuais em jogo, que são mais suscetíveis às discriminações de gênero. Assim, a experiência dos Conselhos mostra que o vínculo entre "sociedade civil" e "representação" é mais favorável à inclusão política das mulheres do que o vínculo entre "indivíduo" e "representação".

Em análise sobre a baixa capacidade inclusiva das mulheres via sistema de cotas, Cypriano, Rezende e Assis (2008, p. 160) alertam para o fato de que a política de cotas contempla apenas a reserva de vagas, "não determinando a necessidade de recrutamento e formação de lideranças femininas para atuação na vida partidária e em cargos eletivos." Ou seja, os vínculos estreitos entre representação nos Conselhos e participação em organizações da sociedade civil fazem, portanto, diferença na capacidade de recrutamento feminino. Essa dimensão também pode ser um elemento que explique a diferenciação nos perfis dos Conselhos Gestores se comparados aos do Orçamento Participativo, onde tendem, de maneira geral, a reproduzir um processo de filtragem, no qual as mulheres formam uma maioria nas bases e uma minoria no Conselho do OP, como demonstram os dados de Gugliano et al. (2008).

\section{Mulher e política: considerações sobre a pre- sença feminina na Política Social}

Os Conselhos Gestores mais estudados no Brasil - e, portanto, dos quais dispomos de mais dados são os da Saúde, Assistência Social e Criança e Adolescente. Isto é compreensível, já que, após a Constituição de 1988, estas foram as primeiras áreas a serem organizadas legalmente de acordo com o princípio descentralizado e participativo dos Conselhos Gestores, implementados nos diferentes níveis de governo $^{8}$. O campo de intervenção desses Conselhos é o da política social, que tem um histórico de atuação feminina e que é, geralmente, compreendido como o campo particular de sua competência. Em alguns dos artigos do dossiê anteriormente mencionado, há vários registros que confirmam a afirmação de que não apenas a atuação das mulheres tem se dado de maneira mais incisiva na área social, como também existe uma percepção de que cabe a elas em particular essa responsabilidade, como é exemplar a seguinte análise:

\footnotetext{
Quando temos mais mulheres no Parlamento ou no Executivo, o tipo de demanda e de políticas implementadas são diferentes, inclusive em função da divisão sexual do trabalho: é apanágio das mulheres cuidar das crianças e, cada vez mais, dos idosos. Existe então esta divisão sexual do trabalho [...] E quando alçada a postos de tomada de decisão, seja de secretária municipal, seja de Vereadora, seja de Prefeita, quase que 'intuitivamente' a mulher encaminha demandas relacionadas com este universo. Segundo a divisão sexual de trabalho, a mulher está para o trabalho reprodutivo assim como o homem está para o produtivo. Da mesma forma, a mulher está para o privado assim como o homem está para o público (COSTA, 2001, p. 221-222).
}

Este registro corrobora as pesquisas que apontam forte correlação entre setor temático e gênero, sugerindo que determinadas áreas de políticas públicas, as de corte social, mobilizam as mulheres para o exercício da participação e da representação em detrimento de outras, que ainda parecem ser consideradas campo de domínio e de competência masculina. De acordo com Bolzendahl e Brooks (2007, p. 1514),

[...] a substantial body of research suggests that women are more invested in, and vocal about, spending tied to important welfare state issues such as health care, family benefits, education, gender policy and childhood development. This is seen in the goals of women's organizations, the answers women given in opinion surveys [...], and in women's priorities as members of legislative bodies. 
A presença de maior número de mulheres nos Conselhos das áreas sociais pode estar associada, em parte, assim, à concepção sobre sua suposta competência intrínseca para os temas enquadrados como sociais e sua ética pautada nos princípios da "solidariedade" e "sensibilidade", que seriam, de acordo com entrevistas realizadas junto às próprias conselheiras, o substrato da lógica de atuação política nos Conselhos ${ }^{9}$. A este tipo de concepção, entretanto, podese reproduzir as críticas que Miguel (2001) endereça a uma determinada vertente feminista, denominada "ética do cuidado", como por exemplo, que ela negligencia ou obscurece os motivos propriamente políticos que respondem pela ausência de preocupação com a área social nas administrações públicas, tornando-a efeito de uma diferença inescapável de gênero; e que, se as mulheres têm uma atuação mais presente nas áreas sociais, esse fato deve-se menos por sua suposta inclinação de "cuidar dos outros", mas porque se trata do "nicho disponível para elas no campo político", o que, obviamente, é uma realidade que pode se alterar na medida em que a presença feminina avance nas áreas até agora "quase monopólio dos homens".

O conteúdo de tais críticas nos remete a considerar o significado histórico dos Conselhos Gestores e as suas consequências para as relações entre a condição feminina e o mundo público. Nesse sentido, temos de lembrar que os Conselhos Gestores resultaram de um longo processo de lutas sociais que procuraram deslocar determinados temas e obrigações do campo das preocupações privadas para o terreno próprio da política e das responsabilidades públicas. Esse foi também o mote principal da segunda onda do movimento feminista e das formulações teóricas desse campo. Ou seja, não é possível desvincular a instituição dos Conselhos da área social do legado das lutas dos movimentos sociais, dentre as quais as feministas ocuparam lugar importante, reclamando mediações e critérios públicos de tratamento para determinados temas e relações antes restritamente dependentes de deliberações privadas, e que sobrecarregavam as mulheres com os cuidados domésticos, dificultando sua saída para o mundo público. Nessa medida, independentemente do grau de comprometimento individual das conselheiras com as bandeiras propriamente feministas, e a despeito da reprodução nesse universo de concepções que podem naturalizar fenômenos que são resultados de processos históricos, a significativa pre- sença das mulheres nos Conselhos Gestores indica também o papel particular que elas vêm desempenhando na efetivação de direitos sociais, cuja ausência responde pelas dificuldades das mulheres saírem do mundo privado.

Uma última observação se faz necessária e diz respeito ao perfil socioeconômico destas mulheres representantes nos Conselhos. Como vimos, elas são, na maioria, brancas, católicas, casadas e com alto nível educacional. Assim, embora os Conselhos venham se constituindo como novas oportunidades de atuação política para as mulheres há que se compreender e analisar quem são estas mulheres, o que desafia uma abordagem que, seguindo avaliação de Allwood e Wadia (2004), considere as íntimas conexões com outras dimensões, aqui mais especificamente classe, religião, etnia e geração.

\section{Referências}

ABERS, R. N.; KECK, M. E. Representando a diversidade: Estado e sociedade e 'relações fecundas' nos Conselhos Gestores. Caderno CRH, Salvador, v. 21, n. 52, p. 99-112, 2008.

ALLWOOD, G; WADIA, K. Increasing Women's Representation in France and India. Canadian Journal of Political Science, Canadá, v. 37, n. 2, p. 375-393, jun. 2004.

BAQUERO, M.; BORBA, J. A (re)valorização dos partidos políticos no Brasil via capital social. Revista de Estudos e Pesquisas sobre as Américas, Brasília, v. 2, n. 1, jan./jun. 2008.

BOLZENDAHL, C; BROOKS, C. Women's Political Representation and Welfare State Spending in 12 Capitalist Democracies. Social Forces, EUA, v. 85, n. 4, p. 1509-1534, jun. 2007.

BURKHART, J. et al. Strategies for Political Participation. Cambridge, Massachusetts: Winthrop Publishers, 1972.

CONWAY, M.; STEUERNAGEL, G.; AHERN, D. Women and Political Participation. Cultural Change in the Political Arena. Washington: CQ Press, 2005.

COSTA, D. M. Capacitação de líderes femininas: reflexões sobre a experiência do IBAM. Revista Estudos Feministas, Florianópolis, v. 9, n. 1, p. 231-224, 2001. 
CYPRIANO, B; REZENDE, D. L; ASSIS, M. P. F. A presença das mulheres brasileiras na política: uma discussão sobre as cotas legislativas sob o enfoque da política da diferença. In: LÜCHMANN, L. H. H; SELL, C. E.; BORBA, J. (Org.). Movimentos sociais, participação e reconhecimento. Florianópolis: Fundação Boiteux, 2008, p. 143-164.

FINAMORE, C. M.; CARVALHO, J. E. C. C. Mulheres candidatas: relações entre gênero, mídia e discurso. Revista Estudos Feministas, Florianópolis, v. 14, n. 2, p. 347-362, 2006.

GROSSI, M. P; MIGUEL, S. M. Transformando a diferença: as mulheres na política. Revista Estudos Feministas, Florianópolis, v. 9, no. 1,p. 167-206, 2001.

GUGLIANO, A. G; ORSATO, A.; LOECK, R. B.; PEREIRA, A. L. A inclusão das mulheres no orçamento participativo de Porto Alegre (2005). In: LÜCHMANN, L. H. H; SELL, C. E.; BORBA, J. (Org.). Movimentos sociais, participação e reconhecimento. Florianópolis: Fundação Boiteux, 2008. p. 165-182.

JUREMA, S. B. Ações e estratégias do CNDM para o 'empoderamento' das mulheres. Revista Estudos Feministas, Florianópolis, v. 9, n. 1, p. 207-212, 2001.

LAVAlle, A. G.; CASTEllo, G. Sociedade civil, representação e a dupla face da accountability: cidade do México e São Paulo. Caderno CRH, Salvador, v. 21, n. 52, p. 67-86, 2008.

LÜCHMANN, L. H. H. A representação no interior das experiências de participação. Lua Nova: Revista de Cultura e Política, São Paulo, s/v, n. 70, p. 139-170, 2007.

.; BORBA, J. Participação e exclusão nos Conselhos Gestores e Orçamentos Participativos. Florianópolis: UFSC, 2009. (Relatório de pesquisa).

MIGUEL, L. F. Política de interesses, política do desvelo: representação e "singularidade feminina". Revista Estudos Feministas, Florianópolis, v. 9, n. 1, p. 253-267, 2001.

MILBRATH, L. Political Participation. Chicago: Rand McNally \& Company, 1972.

PHILLIPS, A. Engendering Democracy. Cambridge: Polity Press, 1991.

TONELLA, C. Poder local e políticas públicas. O papel dos Conselhos Gestores. Maringá: Eduem, 2006.

VERBA, S.; NIE, N. H. Participation in America. Political Democracy and Social Equality. Chicago: Chicago Press, 1987.

\section{Notas}

1 Os dados são provenientes de várias fontes de pesquisa junto a Conselhos de municípios catarinenses. Dados dos conselheiros dos Conselhos Municipais da Assistência Social, do Idoso, da Criança e do Adolescente e da Saúde dos municípios de Itajaí e Chapecó (aplicação de questionários junto a 135 conselheiros - 96,42\%) são provenientes da pesquisa Conselhos Gestores e empoderamento, coordenada pelas professoras Agueda Lenita Wendhausen (Univali) e Maria Elizabeth Kleba (Unochapecó), financiada pelo CNPq e FAPESC. Os dados sobre os Conselhos da Assistência Social, Saúde, Criança e Adolescente do município de Concórdia são provenientes do projeto Participação e exclusão nos Conselhos Gestores e Orçamentos Participativos (CNPq/Funpesquisa), coordenada por Lüchamnne Borba (2009).

2 Surpreendentemente, as pessoas teriam mais disponibilidade para contribuir com dinheiro do que dispor de seu tempo para causas públicas (BURKHART et al, 1972).

3 É importante esclarecer que não estamos usando aqui a ideia de "representação" no sentido de ela indicar uma "representação dos interesses das mulheres", mas para tratar da significativa presença numérica desse gênero nos Conselhos Gestores de Políticas Públicas.

4 Dados relativos aos conselheiros dos Conselhos Municipais de Saúde, Assistência Social, Idoso, Criança e Adolescente dos dois municípios.

5 Com relação à escolaridade, os dois municípios têm cerca de $40 \%$ do seu eleitorado com o primeiro grau incompleto. Já nos Conselhos, apenas 1,42\% em Chapecó e 3,12\% dos participantes em Itajaí estão situados nesta faixa de escolaridade. Os dados se invertem quando consideramos aqueles com o terceiro grau completo. Enquanto nos dois municípios uma pequena parcela do eleitorado possui o terceiro grau (4,14\% em Chapecó e 4,42\% em Itajaí), nos Conselhos, a maioria tem diploma universitário $(75,71 \%$ em Chapecóe 67,18\% em Itajaí).Conforme indicamAberse Keck (2008), alguns estudos sobre o assunto explicam que esse perfil tem íntima relação com o entendimento por parte das organizações da sociedade civil de que a tomada de decisão sobre políticas públicas nos Conselhos Gestores exige saberes especializados e técnicos. De fato, comojá se analisou em trabalho anterior, uma das importantes fontes de legitimidade da representação nessas instâncias recai em critérios de expertise ou qualificação (LÜCHMANN, 2007).

6 No Conselho de Saúde o peso maior da representação recai no setor dos usuários que detém $50 \%$ de seus assentos.

7 O dossiê foi publicado em 2001, na edição de volume 09, número 01 da revista. Sua organização resultou de um seminário realizadoemmaio de 2000, no Congresso Nacional, 
cujo objetivo foi o de avaliar o saldo da política de cotas implantada no Brasil em 1996, bem como refletir sobre estratégias de "empoderamento" das mulheres. Dele participaram parlamentares, prefeitas, candidatas, integrantes de núcleos de mulheres de partidos políticos, sindicatos, representantes de movimentos sociais, pesquisadoras e representantes de Conselhos Municipais, Estaduais e do Conselho Nacional das Mulheres(GROSSI; MIGUEL, 2001).

8 OSistema Único de Saúde(SUS) e oEstatuto da Criançae do Adolescente (ECA) passaram a ter vigência legal em 1990e a Lei Orgânica daAssistência Social (LOAS) é de 1993.

9 Essas entrevistas foram realizadas nos Conselhos Catarinenses já mencionados, e seus resultados são corroborados pela análise de Grossi e Miguel (2001, p. 178189): “A justificativa para a participação das mulheres na política, em muitas das falas vem associada ao reconhecimento de um valor ético, intrínseco às mulheres. Nesse entendimento, uma maior presença das mulheres nos espaços de poder resolveria, por si só, uma equação que associa poder $=$ homem $=$ corrupção. $[$... $]$ Sensibilidade, afeto, carinho, parecem ir de par com as mulheres na maior parte dos discursos do seminário. Estas questões, não por acaso, parecem ser recorrentes no senso comum sobre o verdadeiro papel das mulheres na política, o de tornar os espaços do poder menos ‘áridos', menos crueis e mais dignos.

\section{Lígia Helena Hahn Lüchmann}

ligia@cfh.ufsc.br

Doutorado em Ciências Sociais pela Universidade Estadual de Campinas (Unicamp)

Professora do Departamento de Sociologia e Ciência Política da Universidade Federal de Santa Catarina (UFSC)

\section{UFSC - Departamento de Sociologia e Ciência Política}

Centro de Filosofia e Ciências Humanas

Campus Universitário - Trindade

Florianópolis - Santa Catarina

CEP: 88040-900

\section{Carla Cecília Rodrigues Almeida}

carlaalm@uol.com.br

Doutorado em Ciências Sociais pela Unicamp

Professora do Departamento de Ciências Sociais da Universidade Estadual de Maringá (UEM)

\section{UEM - Departamento de Ciências Sociais}

Av. Colombo, 5790

Jardim Universitário

Maringá - Paraná

CEP: 87020-900 